\title{
Behaviorism and Rationalism
}

\author{
Yan Zhang \\ Nanchang Institute of Science \& Technology \\ Nanchang, Jiangxi, China
}

\begin{abstract}
Every linguistic school has its own characteristics and is related to some certain social needs and bases on certain philosophical ideas, among which rationalism and empiricism have lasting effects on the development of linguistics. Rationalism and empiricism, in different forms, run through all the history of linguistics, we can say, it is because of the existence of philosophical thoughts that various linguistic ideas can appear. Therefore, when this thesis deals with the relationship between linguistics and philosophy, it covers the links and differences of linguistics and philosophy. When it turns to the comparison of empiricism and rationalism, thesis focuses on the similarities and differences.
\end{abstract}

Keywords—philosophy; linguistics; behaviorism; rationalism

\section{INTRODUCTION}

In this thesis, consideration has been given to the explanations of how philosophy and linguistics are linked and related as well as how they differ from each other. Besides, the comparative study of behaviorism and transformative-generative grammar in the history of western linguistics also draws great attention in this thesis. From the title of this thesis, it has been observed that behaviorism in the angle of linguistics and rationalism in the philosophy are involved. As we all know, linguistics, from the time it was created, is influenced by philosophy.

\section{THE RELATIONSHIP BETWEEN LINGUISTICS AND PHILOSOPHY}

\section{A. The Links between Linguistics and Philosophy}

Linguistics, from its beginning, is influenced by philosophy, because philosophy then was more famous and influenced people to their hearts. Besides, linguistic theories of methodologies will lose solid base if there are no philosophical achievements. Many famous creators and practitioners of linguistic theories all have received trainings in formal philosophy, formal logic or combinations of them. And many other linguists learned some certain philosophical hypotheses through college education.

Linguistics, as an experiential science which studies language and philosophy which aims at discovering the essence of the world and human recognition are rather than in breeding and deriving relation, they are interactional, interdependent and mutually incentive. It can be said that linguistics study without philosophy will lead to abstract and empty.

\section{B. The Differences between Linguistics and Philosophy}

Conversely, philosophy is also influenced by linguistics, in that linguistics enriches philosophy by providing new inspirations and contents. Language is of great importance to philosophical study. Sometimes, linguistic theory can help explain philosophical phenomena.

\section{COMPARISON OF EMPIRICISM AND RATIONALISM}

\section{A. The Similarities}

Empiricism and rationalism are both philosophical schools and bear the same philosophical ways of thinking. People who believe rationalism do not deny the fact that experience is indeed a source of knowledge and they also admitted that some knowledge gains from experience is reliable. And people who support empiricism also admitted that rational knowledge is more reliable than perceptual knowledge and rational deduction is essential within certain boundaries.

\section{B. The Differences}

The opposition of empiricism and rationalism mainly lies in knowledge and the ways that people gain knowledge and the difference mainly involves the following aspects. Firstly, the origin of human knowledge, empiricism maintains it is perceptual experience, while rationalism believes human knowledge originates from inherent or innate ideas which are absolutely clear and correct. Secondly, the ways or steps of getting common knowledge, the former prefers to induction, while the later prefer to deduction. Then, which kind of knowledge is definite and truthful. Fourthly, whether human beings' cognitive ability is supreme or not, is this kind of ability restricted or not? Empiricism thinks it is supreme and people can recognize the world without restriction, while rationalism maintains that human cognitive ability is not supreme and it must be restricted with some certain range, people cannot get to know and understand everything in this world. Comparatively, rationalism emphasizes more on the problems and aspects which are related to rationality, while empiricism pays more attention to problems and aspects which related to experience.

\section{THE REASONS WHY BEHAVIORISM IS REPLACED BY RATIONALISM}

Structuralism was once dominated the western linguistic world and behaviorism is the basis of structuralism, so behaviorism is also very famous during that time. However, after $1950 \mathrm{~s}$, behaviorism is gradually replaced by rationalism in terms of its dominating position. 
Behaviorism has its own intrinsic disadvantages. Firstly, behaviorism emphasizes children's imitation and repetition of what they hear. Secondly, behaviorists cannot explain why children sometimes say some sentences that they never heard before, and why they know to use some words under some language context. A linguist once observed the process of three children's acquiring sequence has no regular relations with their mother' teaching sequence, so this result shows that we cannot explain children's language acquisition just like the explanation of their general habitual behaviors. So, behaviorism cannot all-grounded explain the complete process of language acquisition. Besides, rationalism has great and deep influences on people's mind, and people believe the doctrines of rationalism. With the rapid development of the whole society, especially the natural science and technology, rationalism has its biological basis while behaviorism has not, so, from this point of view, rationalism is more influential and has stronger life power than behaviorism.

\section{CONCLUSION}

Linguistics is a prospective science; it was and still is influenced by philosophy in that philosophy provides solid bases for linguistics and conversely, linguistics also has some positive effects on philosophy. The development of linguistics contributes to the spread of philosophical ideas. In philosophical field, there is fierce competition of empiricism and rationalism, which is mainly presented in the issues of the origin of human knowledge, the truth of language, and the emphasizing degree of experience.

\section{REFERENCES}

[1] Chen Xiuzai, 2008, Empiricism and Rationalism in European History of Philosophy[J], People's Publishing House.

[2] George Yule, the study of language [M], second edition.

[3] Linguistics Treatise [A], page157-158, Peking University.

[4] Neil Smith, Chomsky: Ideas and Ideals [M], Cambridge University Press.

[5] William M. Baum, 2005, Understanding Behaviorism [M], Blackwell Publishing Ltd

[6] Zhou Pin, Explanation of the Interaction between Linguistics and Philosophy within the Framework of LMR-Relation [J], Foreign Language Periodicals. 